
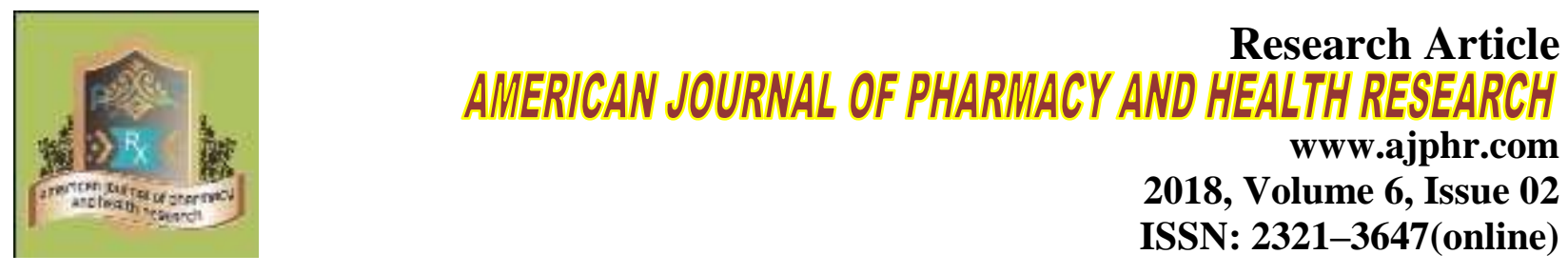

\title{
Antioxidant, Free Radical Scavenging and In Vitro Cytotoxic studies of Different Solvent Extracts from the Stem Bark of Bauhinia Variegata Linn.
}

\author{
Trupesh Pethani $^{\mathbf{1}^{*}}$, Mayuri Thumar ${ }^{2}$, Vishal Airao ${ }^{1}$, Ashvin Dudhrejiya ${ }^{2}$ \\ 1. Department of Pharmaceutical Sciences, Saurashtra University, Rajkot, Gujarat, India. \\ 2. B.K. Mody Government Pharmacy College, Rajkot, Gujarat, India.
}

\begin{abstract}
Bauhinia variegata (Family: Fabaceae) is well-known medicinal plant used from the ancient era to till date for their medicinal values. The powerful biological activities as exhibited by plant flavonoids posed the need of determining their contents in B. variegata stem bark. In view of its wide use and its chemical compositions, this study was aimed at examining and comparative analysis of the antioxidant and anticancer activities of the different extracts of stem bark. Antioxidant activity of extracts was expressed as percentage of DPPH, super oxide and nitric oxide free radicals inhibition and expressed as $\mathrm{IC}_{50}$ values $(\mu \mathrm{g} / \mathrm{mL})$. Methanolic extracts of $B$. variegata showed the highest amount of and flavonoid contents and reducing capacity whereas, chloroform and dichloromethane extracts of $B$. variegata showed pronounced cytotoxic effect against HCT-116, A549 and ethyl acetate extracts showed pronounced cytotoxic effect against Ovcer-5 human cancer cell lines. The order of antioxidant activity in B. variegata extracts displayed from higher to lower level as methanol, hydro-alcoholic, ethyl acetate, chloroform, dichloromethane and $\mathrm{n}$-hexane extracts of stem bark of B. variegata. Commercial standards were taken as control showed highest antioxidant power in the present study. Chemical components of $B$. variegata have good antioxidant capacities and this species could be used as a potential source of new natural antioxidants.
\end{abstract}

Keywords: Antioxidant; Bauhinia variegata; Cytotoxicity; Stem bark extract; Total flavonoids. 


\section{INTRODUCTION}

Free radical or active oxygen scavengers, naturally occurring from plant sources have been identified as antioxidant compounds ${ }^{[1]}$. Different forms of reactive oxygen species (ROS) are constantly generated for specific metabolic requirement and quenched by an efficient antioxidant network in the body. In degenerative diseases, generation of these ROS exceeds the levels of antioxidant mechanism leading to oxidative damage of tissues and biomolecules, eventually causing to disease conditions. ${ }^{[2]}$. Moreover, ROS such as superoxide anion, hydroxyl, peroxynitrite and nitric oxide radical and nonradical of oxygen such as hydrogen peroxide, hypochlorous acid and singlet oxygen plays a key role for the induction of oxidative stress. In human body, these free radicals are generated by the biochemical reactions and involved in the structural, molecular and functional damage to the neurons, proteins, lipids, nucleic acids and DNA. Current research into free radicals has confirmed that natural antioxidants which neutralize free radicals have central importance in the prevention of vascular diseases, some forms of cancer and oxidative stress responsible for DNA, protein and membrane damage ${ }^{[3,4]}$. Recently, synthetic antioxidants are more used as food additives for the treatment of various diseases, but their degradation products are carcinogenic ${ }^{[5,6]}$. A number of natural products, such as flavonoids, coumarins, curcuminoids or terpenes, isolated from plants have shown potent antioxidant activity and low toxicity ${ }^{[7]}$. There is a growing interest in the pharmacological evaluation of various plants used in Indian traditional medicine. For this, main focus of research is based on the identification and isolation of new antioxidants from natural sources ${ }^{[8,9]}$

Bauhinia variegata Linn. (Family: Fabaceae) commonly known as 'Camel's foot tree or Orchid tree', is widely distributed in most tropical countries including Africa, Asia and South America. Moreover, the plant is being used as a medicine for jaundice, leprosy, smallpox, and skin complaints in Indian traditional system of medicine. ${ }^{[10,11]}$. The plant also possessed diverse pharmacological activities such as anti-oxidant, hepatoprotective, hypoglycemic, antiproliferative, and many more. ${ }^{[5,6]}$.The biological properties of different Bauhinia spp. phytopreparations and pure metabolites have been investigated in numerous experimental in vivo and in vitro models. The secondary metabolites produced by this genus, particularly the flavonoids, make the plants under this genus an important source of potential phytotherapeutic and medicinal agents. Almost all studies focused on in vitro cytotoxicity of alcoholic extract from $B$. variegata stem bark ${ }^{[12]}$. Numerous studies were reported for successive extraction only for leaves of B. variegata ${ }^{[13]}$. 
In context to this, the present study was designed to evaluate the in vitro antioxidant activity, cytotoxic activities and concentration of flavonoids of six different extracts such as n-hexane, dichloromethane, chloroform, ethyl acetate; methanol and hydro alcoholic of B. variegata stem bark.

\section{MATERIALS AND METHOD}

\section{Chemicals and reagents}

Trichloroacetic acid (TCA) and ferric chloride were purchased from Merck, India. 1, 1-diphenyl2-picrylhydrazyl (DPPH), nitro-blue tetrazolium (NBT), potassium ferricyanide, ascorbic acid, gallic acid (GA), and sodium nitrite were purchased from Sigma-Aldrich Co. (St. Louis, MO, USA). Folin-ciocalteu reagent was purchased from SD Fine Chemicals, Mumbai, India. Sulfanilamide was purchased from NR Chemicals Pvt Ltd, Mumbai, India. Sodium nitroprusside and riboflavin were obtained from HiMedia Laboratories Pvt Ltd, Mumbai, India. All solutions were freshly prepared in distilled water. Other reagents and solvents used were of analytical grade and obtained from local vendors.

\section{Sample collection and extraction}

Stem bark of B. variegata was collected from Botanical garden of Saurashtra University, Rajkot, Gujarat, India. The bark was washed and cut into small pieces and then air dried under shade. The plant was taxonomically identified and authenticated by Dr. Sunita Garg, National Institute of Science Communication and Information Resources (NISCAIR), New Delhi, India. A voucher specimen (SU/DPS/HERB/61) was retained in the depository of Department of Pharmaceutical Sciences, Saurashtra University, Rajkot, Gujarat, India for future reference. The stem bark of $B$. variegata was coarsely powdered and passed through sieve (\#60). The obtained powder (100 g) was then sequentially extracted with different solvents by increasing in polarity order i.e. nHexane (BNE), dichloromethane (BDE), chloroform (BCE), ethyl acetate (BEE), methanol (BME), hydro alcohol (BHE) for $48 \mathrm{hr}$ at $\leq 40{ }^{\circ} \mathrm{C}$ using soxhlet apparatus ${ }^{[7]}$. The powdered material was dried each time before extracting with next solvent in oven below $50{ }^{\circ} \mathrm{C}$. After filtration, the resultant extracts were concentrated under reduced pressure at room temperature using rotary vacuum evaporator. The final obtained extracts were weighed with the solvent and calculate its percentage in terms of the air-dried weight of the plant material. Further, the concentrated extract was dried in desiccator and stored in vacuum sealed air tight containers in freezer until further use. 


\section{Estimation of total flavonoid content}

Total flavonoid content was estimated in all extracts of stem bark of B.variegata by the method described by Zhishen et al. ${ }^{[14]}$, using quercetin (QE) as standard. All extracts were dissolved in DMSO to make the final concentration $1 \mathrm{mg} / \mathrm{mL}$. Briefly, $0.5 \mathrm{~mL}$ of aliquot of different extracts were added to $75 \mu \mathrm{L}$ of $\mathrm{NaNO}_{2}(5 \%)$ solution. After $5 \mathrm{~min}, 150 \mu \mathrm{L}$ of aluminium chloride (10\%) solution was added and allowed to stand for another $5 \mathrm{~min}$. Then, $0.5 \mathrm{~mL}$ of $1 \mathrm{M} \mathrm{NaOH}$ and 2.5 $\mathrm{mL}$ of distilled water was added. The solutions were mixed and absorbance was measured at 510 $\mathrm{nm}$ using distilled water as blank. All experiments were carried out in triplicate. Total flavonoid content was calculated as $\mathrm{mg}$ of $\mathrm{QE}$ equivalent per $\mathrm{g}$ of dry extract, using the liner equation based on the calibration curve:

$$
\mathrm{Y}=0.0011 \mathrm{X}+0.0082, \mathrm{R}^{2}=0.9927
$$

Where, $\mathrm{X}$ is absorbance and $\mathrm{Y}$ is $\mathrm{mg}$ of QE equivalent per $\mathrm{g}$ of extract.

\section{Antioxidant assays}

\section{Determination of DPPH radical-scavenging capacity}

DPPH free radical scavenging capacity was measured according to method described by Miliauskas, et al. ${ }^{[15]}$. Briefly, $25 \mathrm{mg}$ of DPPH was dissolved in 1liter of methanol. An aliquot of methanol containing different concentrations $(0.1 \mathrm{~mL})$ of all extracts such as BNE, BDE, BCE, BEE, BME and BHE $(30 \mu \mathrm{g} / \mathrm{mL}, 75 \mu \mathrm{g} / \mathrm{mL}, 150 \mu \mathrm{g} / \mathrm{mL}, 300 \mu \mathrm{g} / \mathrm{mL}, 450 \mu \mathrm{g} / \mathrm{mL}$ and 600 $\mu \mathrm{g} / \mathrm{mL}$ ) was added to $3.9 \mathrm{~mL}$ of DPPH solution. Absorbance was taken after $15 \mathrm{~min}$. at $516 \mathrm{~nm}$ using UV-1700 Simadzu corporation, Japan. IC $_{50}$ values for all extracts were then calculated and compared with that of ascorbic acid as a standard. Lower absorbance of the reaction mixture indicates higher free radical-scavenging activity.

The percent DPPH scavenging activity was calculated using the following equation:

$$
\% \text { DPPH scavenging activity }=\frac{A_{\text {control }}-A_{\text {sample }}}{A_{\text {control }}} \times 100
$$

Where, $\mathrm{A}_{\text {control }}$ is the absorbance of control and $\mathrm{A}_{\text {sample }}$ is the absorbance of test sample after 15 min incubation.

\section{Determination of nitric oxide ( $\mathrm{NO}^{\circ}$ ) radical scavenging activity}

The method described by Sreejayan and Rao, ${ }^{[16]}$ was used for the determination of NO scavenging activity of all different extracts. In concise, all different concentrations of extracts were taken in separate tubes and made the final volume up to $1000 \mu \mathrm{L}$ with methanol. To each tube, $2.0 \mathrm{~mL}$ of sodium nitroprusside $(10 \mathrm{mM})$ in phosphate buffer saline was added. The resulting solutions were incubated at room temperature for $150 \mathrm{~min}$. The similar procedure was 
repeated with methanol as blank which served as control. After the incubation, $5 \mathrm{~mL}$ of Griess reagent was added to each tube including control. The absorbance of chromophore formed was measured at $546 \mathrm{~nm}$. Curcumin was used as standard in this assay. The amount of NO inhibition is calculated by following equation:

$$
\% \text { inhinition of } N O \text { radical }=\frac{A_{0}-A_{1}}{A_{0}} \times 100
$$

Where, $\mathrm{A}_{0}$ is the absorbance before reaction and $\mathrm{A}_{1}$ absorbance after reaction had taken place with Griess reagent.

\section{Super oxide free radical scavenging activity}

The superoxide radical scavenging activity was measured as described by Robak and Gryglewski ${ }^{[17]}$. Briefly, $100 \mu \mathrm{L}$ riboflavin solution $(20 \mu \mathrm{g}), 200 \mu \mathrm{L}$ EDTA solution $(12 \mathrm{mM}), 200 \mu \mathrm{L}$ methanol and $100 \mu \mathrm{L}$ NBT solution $(0.1 \mathrm{mg})$ were mixed with different volumes of extracts in test tubes and the reaction mixture was diluted up to $3 \mathrm{~mL}$ with phosphate buffer $(50 \mathrm{mM}, \mathrm{pH}$ 7.4). The entire reaction assembly was enclosed in a box lined with aluminium foil. Identical tubes with reaction mixture were kept in the dark and served as blanks. The absorbance of solution was measured at $590 \mathrm{~nm}$ using phosphate buffer as blank after illumination for 5 min. The percentage inhibition of superoxide anion generation was calculated using the following formula:

$$
\% \text { inhinition of SO radical }=\frac{A_{0}-A_{1}}{A_{0}} \times 100
$$

Where, $\mathrm{A}_{0}$ is the absorbance of the control, and $\mathrm{A}_{1}$ is the absorbance of extracts/standard. $\mathrm{IC}_{50}$ value and the percentage inhibition were calculated for all extracts and compared with ascorbic acid which was used as positive control in this assay.

\section{Reducing power (RP) assay}

RP assay of all different extracts was evaluated by the method described by Oyaizu ${ }^{[18]}$. In brief, $2.5 \mathrm{~mL}$ of $0.2 \mathrm{M}$ phosphate buffer ( $\mathrm{pH} 6.6)$ and $2.5 \mathrm{~mL}$ of potassium hexacynoferrate $(1 \% \mathrm{w} / \mathrm{v})$ were added to $1.0 \mathrm{~mL}$ of different concentrations of extracts. The resulting mixture is incubated at $50{ }^{\circ} \mathrm{C}$ for $20 \mathrm{~min}$, followed by the addition of $2.5 \mathrm{~mL}$ of TCA $(10 \% \mathrm{w} / \mathrm{v})$. The mixture is then centrifuged at $3000 \mathrm{rpm}$ for $10 \mathrm{~min}$ to collect the upper layer of the solution $(2.5 \mathrm{~mL})$, mixed with distilled water $(2.5 \mathrm{~mL})$ and $0.5 \mathrm{~mL}$ of ferric chloride $(0.1 \%, \mathrm{w} / \mathrm{v})$ solution. The absorbance is then measured at $700 \mathrm{~nm}$ against blank sample.

\section{In vitro cytotoxicity study}

Cell lines, growth conditions, and treatment 
Cancer cell lines, namely, ovary (OVCAR-5), lungs (A-549) and colon (HCT-116) cell lines were procured from National Centre for Cell Sciences, Pune, India. Cell lines were grown and maintained in RPMI-1640 medium, pH 7.4 supplemented with 10\% fetal bovine serum (FBS), 100 units/mL penicillin, $100 \mu \mathrm{g} / \mathrm{mL}$ streptomycin, and $2 \mathrm{mM}$ glutamine cells in $\mathrm{CO}_{2}$ incubator (Heraeus, GmbH Germany) at $37{ }^{\circ} \mathrm{C}$ in the presence of $95 \%$ humidity and $5 \% \mathrm{CO}_{2}$.

\section{Sulforhodamine B (SRB) cytotoxicity assay}

The in vitro cytotoxicity of leaf extracts was determined using method described by Skehan et al. ${ }^{[19]}$. Cell suspensions $(100 \mu \mathrm{L}, 10,000-20000 \mathrm{cells} / \mathrm{mL}$ depending upon mass doubling time of cells) was grown in 96-well tissue culture plate and incubated for $24 \mathrm{~h}$. Stock solutions of test extracts were prepared in DMSO and serially diluted with growth medium to obtain desired concentrations. $100 \mu \mathrm{L}$ of test extract $(100 \mu \mathrm{g} /$ well $)$ was then added to the wells, and cells were further incubated for another $48 \mathrm{~h}$. The cell growth was arrested by layering $50 \mu \mathrm{L}$ of $50 \%$ TCA and incubated at $4{ }^{\circ} \mathrm{C}$ for an hour followed by washing with distilled water and then air dried. SRB (100 $\mu \mathrm{L}, 0.4 \%$ in $1 \%$ acetic acid) dye was then added to each well, and plates were incubated at room temperature for $30 \mathrm{~min}$. The unbound SRB dye was washed with $1 \%$ acetic acid and plates were allowed to air dry. Finally, tris-HCl buffer (100 $\mu \mathrm{L}, 0.01 \mathrm{M}, \mathrm{pH} 10.4)$ was added, and absorbance was read on ELISA reader at $540 \mathrm{~nm}$. Suitable blanks and positive controls were also included. Each test was done in triplicate. The values reported here are mean $\pm \mathrm{SD}$ of three experiments.

\section{Statistical analysis}

Experimental results from the present study were expressed as means \pm SD of three parallel measurements. Regression analysis was performed to calculate the dose response relation between all the extracts. Linear regression analysis was done to find out the correlation coefficient. Data were analyzed using one-way analysis of variance (ANOVA) and values $\mathrm{p}<$ 0.05 were considered as significant. Correlation and regression analysis was carried out using Microsoft Excel and Graph Pad Prism (Version 5.0) software.

\section{RESULTS AND DISCUSSION}

\section{Recovery percent and flavonoid content of $B$. variegata extracts}

Table 1 depicts the total flavonoid contents as well as \% yield of the different solvent extracts of B. variegata. The $\%$ yield of extract obtained from $100 \mathrm{~g}$ of dry plant material was estimated for each extract (Table 1). The amount of extractable compounds, expressed as percentage by weight of dried powder. The lowest and highest \% yield was found to be $0.13 \%$ of the chloroform 
extract and $4.78 \%$ of the methanol extract, respectively. The concentration of total flavonoids in different extracts of B. variegata ranged from 4.57 - $62.56 \mathrm{mg}$ of QE/g of extract. Methanolic, ethyl acetate and hydroalcoholic extracts contained the highest flavonoid concentration as compared to other extracts.

Table 1: The yields extraction and total flavonoid contents in different extracts of stem bark of $B$. variegata

\begin{tabular}{ccc}
\hline $\begin{array}{c}\text { B. variegata } \\
\text { Extracts }\end{array}$ & Yields $(\%)$ & $\begin{array}{c}\text { Total Flavanoids content }^{\mathbf{a}} \\
(\mathbf{m g} \text { QE/g) }\end{array}$ \\
\hline BME & 4.78 & $62.56 \pm 0.643$ \\
BHE & 3.28 & $48.49 \pm 0.719$ \\
BEE & 1.03 & $53.15 \pm 0.547$ \\
BCE & 0.75 & $21.33 \pm 0.362$ \\
BDE & 0.44 & $9.18 \pm 0.401$ \\
BNE & 0.13 & $4.57 \pm 0.333$ \\
\hline
\end{tabular}

${ }^{\mathrm{a}}$ Each value represents the mean \pm SD of three experiments.

${ }^{b} \mathrm{mg}$ of quercetin equivalent per $\mathrm{g}$ of dry stem bark extract.

\section{Antioxidant activity of $B$. variegata extracts}

\section{DPPH free radical-scavenging activity of $B$. variegata extracts}

Figure 1 represents free radical scavenging capacities of the different solvent extracts estimated by DPPH assay. This activity can be evaluated by the determination of the $\mathrm{IC}_{50}$ values which corresponds to the amount of extract required to scavenge $50 \%$ of DPPH radicals present in the reaction mixture. Higher $\mathrm{IC}_{50}$ values indicate low antioxidant activity. The present study revealed that methanolic fraction was the most potent radical scavenger followed by hydroalcoholic and ethyl acetate extracts whereas, chloroform, dichloromethane and n-hexane extracts did not showed any significant antioxidant activities (Table 2).

Table 2: Evaluation of the $\mathrm{IC}_{50}$ value in $\mathrm{DPPH}$ free radical scavenging, Nitric oxide scavenging and super oxide free radical scavenging assay of $\boldsymbol{B}$. variegata stem bark extracts.

\begin{tabular}{cccc}
\hline $\begin{array}{c}\text { B. } \text { variegata } \\
\text { Extracts/standards solution }\end{array}$ & $\begin{array}{c}\mathbf{I C}_{\mathbf{5 0}}(\mathbf{D P P H})^{\mathbf{a}} \\
\boldsymbol{\mu} \mathbf{g} / \mathbf{m L}\end{array}$ & $\begin{array}{c}\mathbf{I C}_{\mathbf{5 0}}(\mathbf{N i t r i c} \text { Oxide })^{\mathbf{a}} \\
\boldsymbol{\mu g} / \mathbf{m L}\end{array}$ & $\begin{array}{c}\mathbf{I C}_{\mathbf{5 0}} \mathbf{( S u p e r ~ O x i d e}^{\mathbf{a}} \\
\boldsymbol{\mu g} / \mathbf{m L}\end{array}$ \\
\hline BNE & $>600$ & $>600$ & $>600$ \\
BDE & $>600$ & $>600$ & $>600$ \\
BCE & $577.23 \pm 4.7$ & $454.45 \pm 12.4$ & $512.66 \pm 4.8$ \\
BEE & $533.93 \pm 2.8$ & $342.85 \pm 9.4$ & $441.22 \pm 6.0$ \\
BME & $258.30 \pm 6.5$ & $220.11 \pm 7.6$ & $234.63 \pm 8.5$ \\
BHE & $463.72 \pm 4.0$ & $292.38 \pm 9.7$ & $413.39 \pm 11.7$ \\
Ascorbic acid & $14.24 \pm 1.5$ & - & $18.62 \pm 2.0$ \\
Curcumin & - & $12.53 \pm 3.5$ & - \\
\hline
\end{tabular}

${ }^{\mathrm{a}}$ Each value represents the mean \pm SD of three experiment. 


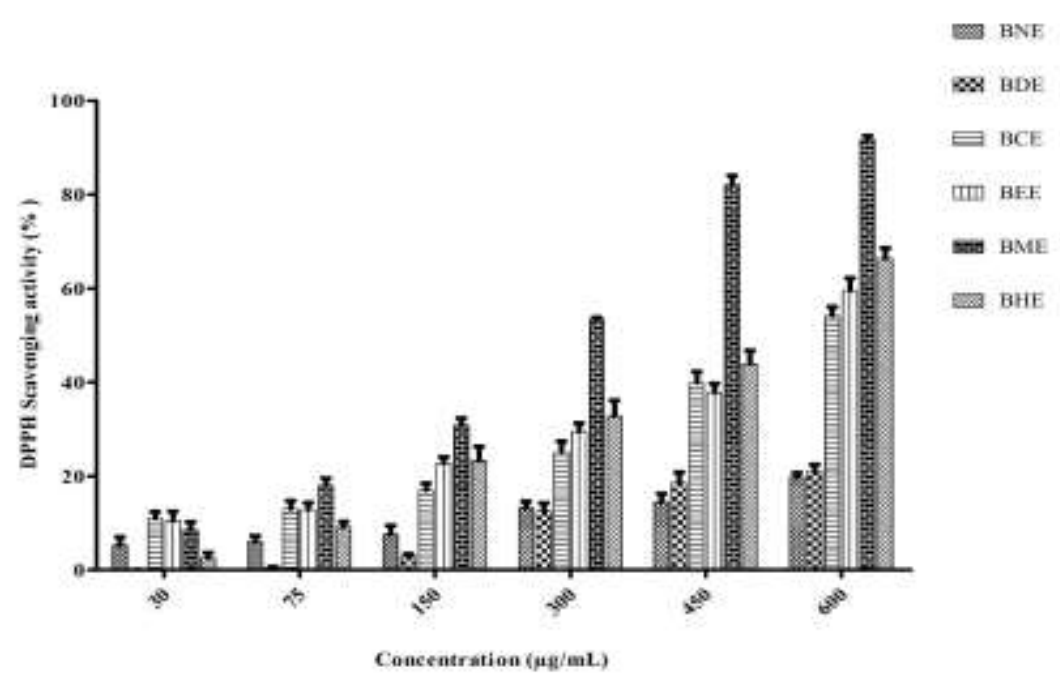

Figure 1: The DPPH free radical-scavenging activity of $B$. variegata stem bark extracts at different concentrations $(\mu \mathrm{g} / \mathrm{mL})$. BNE: n-Hexane, BDE: Dichloromethane, BCE: Chloroform, BEE: Ethyl acetate, BME: Methanol, BHE: Hydroalcoholic extract. Each value represents the mean \pm SD of three experiments.

\section{NO scavenging activity}

As illustrated in Figure 2, the NO scavenging activity of different solvent extracts was concentration dependent. Table 2 summarize the $\mathrm{IC}_{50}$ value of each extracts. Curcumin was used as a standard.

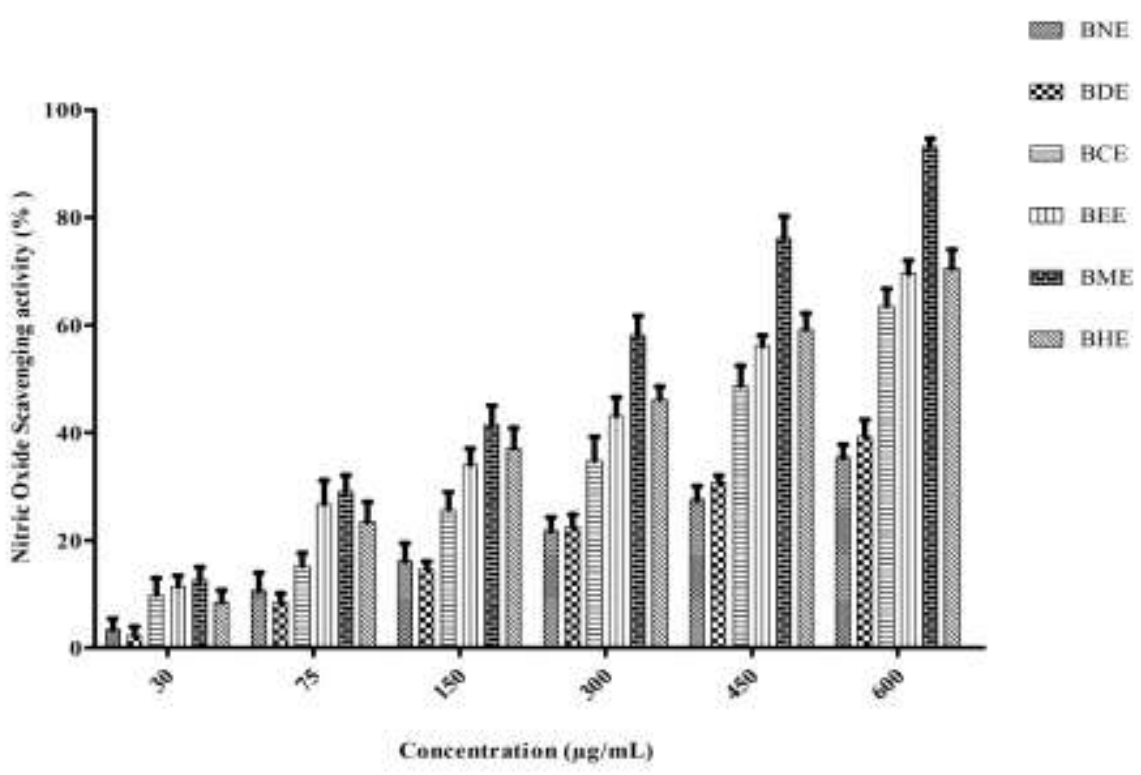

Figure. 2: The nitric oxide scavenging activity of $B$. variegata stem bark extracts at different concentrations $(\mu \mathrm{g} / \mathrm{mL})$. BNE: n-Hexane, BDE: Dichloromethane, BCE: Chloroform, BEE: Ethyl acetate, BME: Methanol, BHE: Hydroalcoholic extract. Each value represents the mean \pm SD of three experiments.

Super oxide free radical scavenging activity 
The resultant $\mathrm{IC}_{50}$ of super oxide radical scavenging activities of the different solvent extracts were summarized in table 2 and concentration dependant effect was described graphically in Figure 3. Ascorbic acid was used as standard.

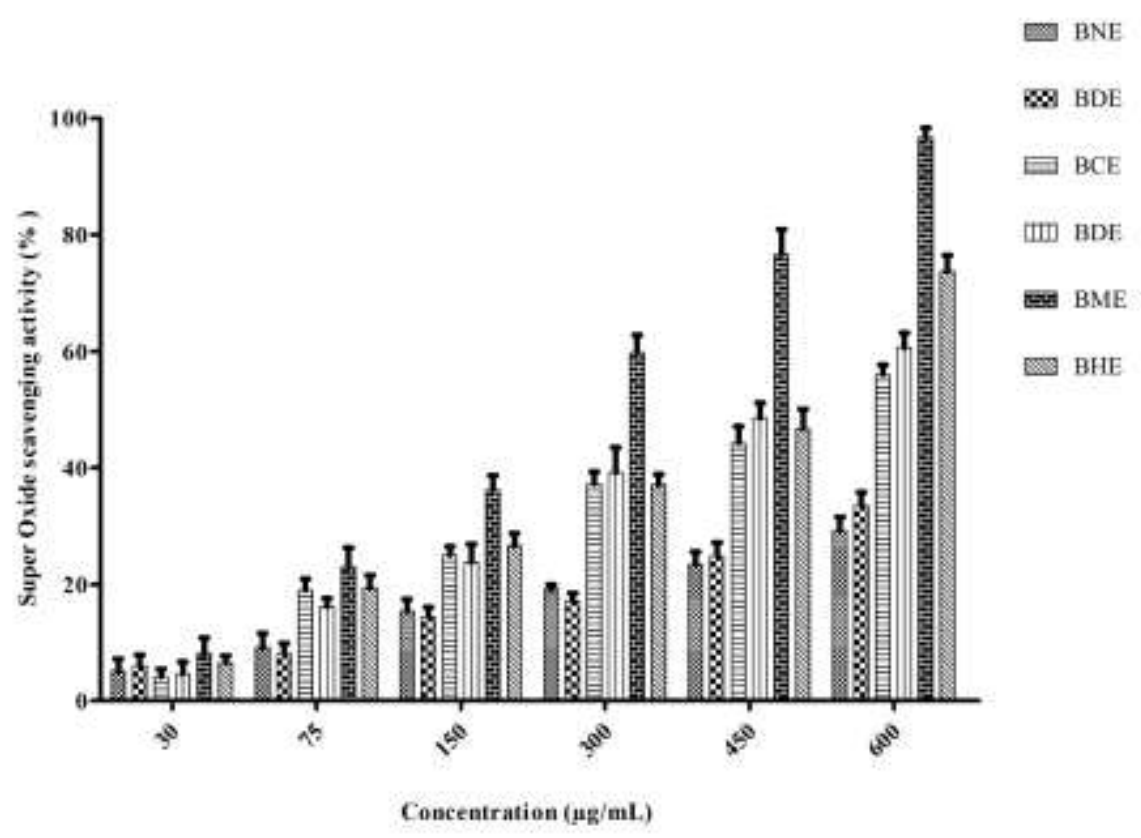

Figure. 3: The super oxide free radical scavenging activity of $B$. variegata stem bark extracts at different concentrations $(\mu \mathrm{g} / \mathrm{mL})$. BNE: n-Hexane, BDE: Dichloromethane, BCE: Chloroform, BEE: Ethyl acetate, BME: Methanol, BHE: Hydroalcoholic extract. Each value represents the mean \pm SD of three experiments.

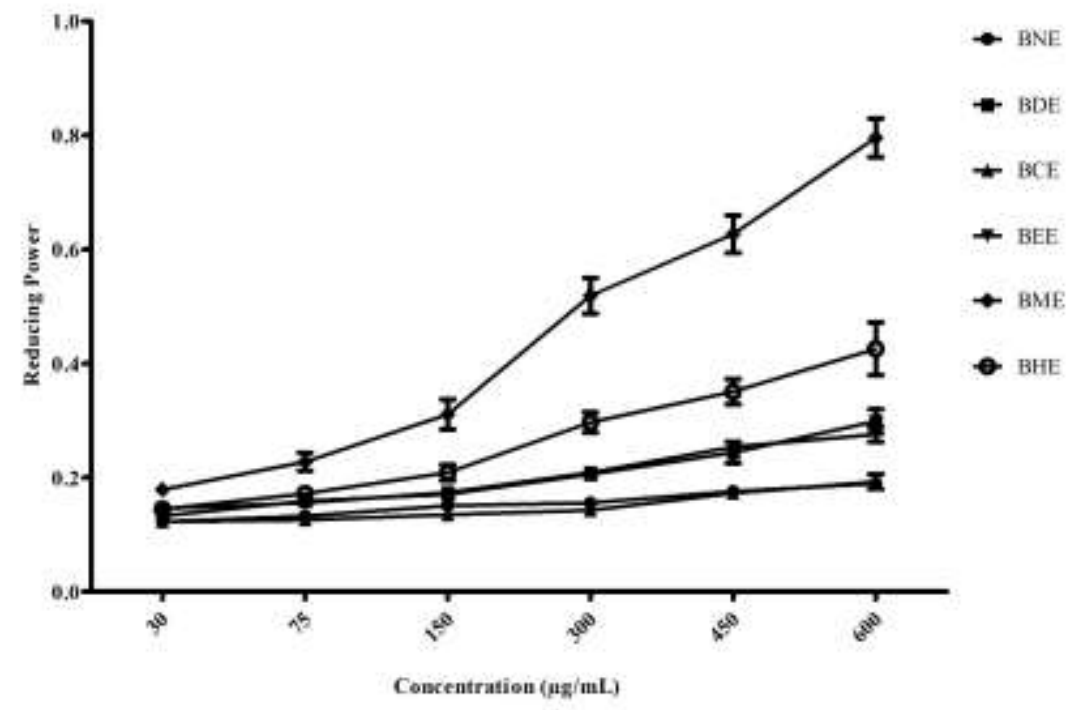

Fig. 4: The graphical representation of reducing power assay of $B$. variegata stem bark extracts at different concentrations $(\mu \mathrm{g} / \mathrm{mL})$. BNE: n-Hexane, BDE: Dichloromethane, BCE: Chloroform, BEE: Ethyl acetate, BME: Methanol, BHE: Hydroalcoholic extract. Each value represents the mean \pm SD of three experiments. Ascorbic acid (AA) was used as a standard. 


\section{Reducing power assay}

The reducing power assay is often used to evaluate the ability of an antioxidant to donate an electron. The higher the absorbance of the reaction mixture, the higher would be the reducing power. Reducing power of different extracts increased with the concentration of the extract. As shown in Figure 4, the reducing power of different extracts was found to be in order of $\mathrm{BME}>\mathrm{BHE}>\mathrm{BEE}>\mathrm{BCE}>\mathrm{BDE}>\mathrm{BNE}$. The reducing power of standard ascorbic acid was found to be higher than all other extracts.

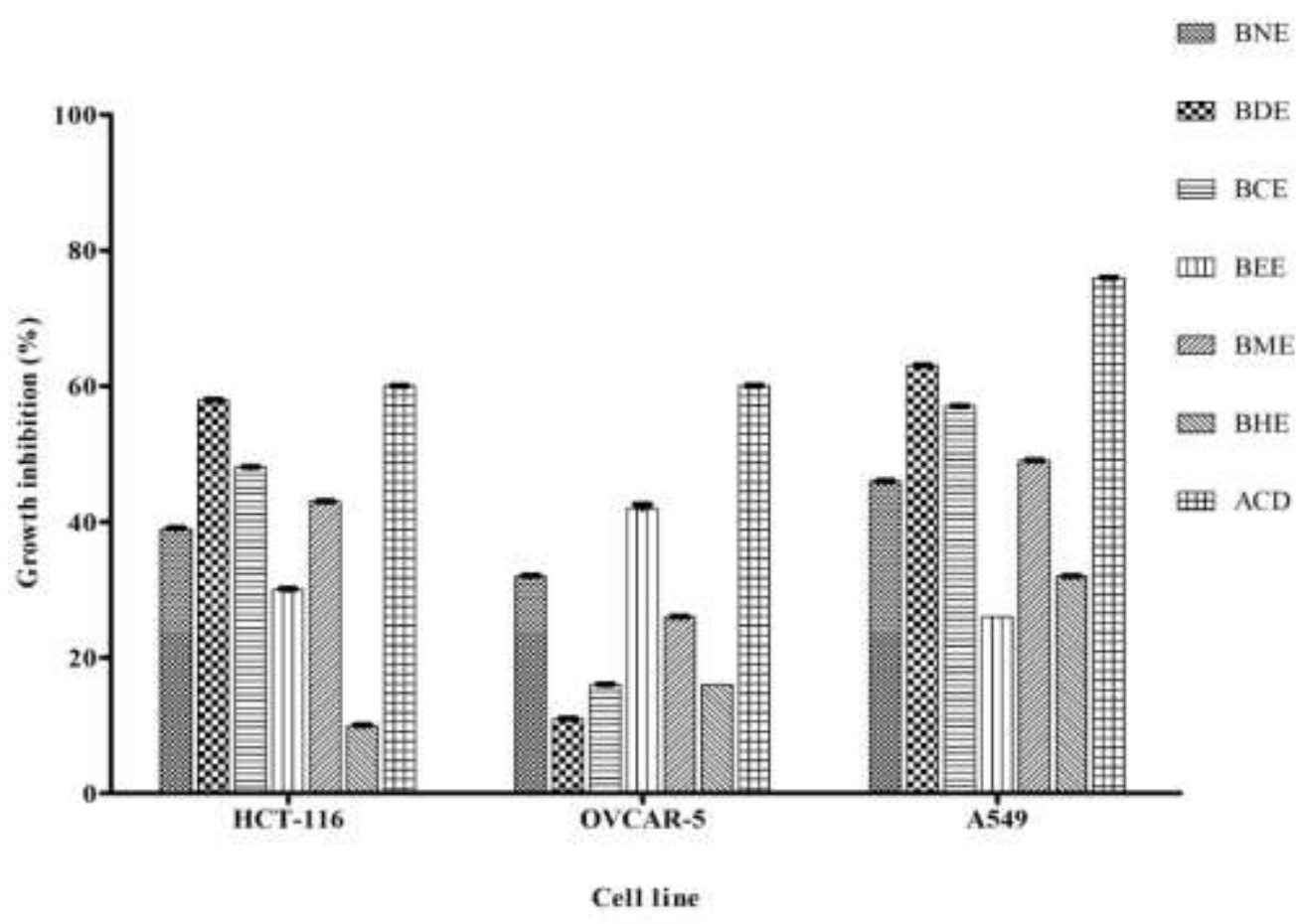

Figure 5: Cytotoxic activity of $B$. variegata stem bark extracts against cancer cell lines using SRB assay. Percentage growth inhibition of HCT-116 (Colon), OVCAR-5 (Ovary), and $\mathrm{A549}$ (Lung) cancer cell lines was assayed at $100 \mu \mathrm{g} / \mathrm{mL}$ concentration of extracts. BNE: n-Hexane, BDE: Dichloromethane, BCE: Chloroform, BEE: Ethyl acetate, BME: Methanol, BHE: Hydroalcoholic extract. ACD: Anticancer drugs [5-flurouracil (1 $\mu$ M) against colon and ovary, Paclitaxel $(1 \mu \mathrm{M})$ against lung cancer cell lines]. Data represent mean \pm SD of three replicates $(\mathrm{P}<\mathbf{0 . 0 5})$

In vitro cytotoxic activity

Figure 5 represents the values of in vitro cytotoxic activity of different solvent extracts of $B$. variegata. Chloroform extract of the plant was found to be the most active and exhibiting \% growth inhibition of about 48\% and 57\% against colon (HCT-116), and lung (A549) cell lines whereas, EA extract was found $42 \%$ against ovary (Ovcar-5), respectively. Performance index of DCM and Chloroform extracts against A549 cell lines were almost similar and showed about $57 \%$ growth inhibition. The rest of the extracts showed lower anticancer activity $(<45 \%)$. In 
general, colon (HCT-116) and lung (A549) cell lines exhibited greater sensitivity to B. variegata extracts. Hydroalcoholic extract was least effective against most of the cancerous cells.

The results of the present study demonstrated that stem bark extracts of B. variegata, particularly methanol, hydro alcoholic and ethyl acetate extracts, showed potent antioxidant activities against DPPH radicals.

The generation of oxidative stress due to imbalance between reactive oxygen species (ROS) and antioxidant defence mechanisms leads to cellular and intracellular damage. Phytoconstituents present in plants such as phenolics and flavonoids play a pivotal role in neutralization of ROS and act as strong natural antioxidants and thus play an important role in maintenance of health. The total flavonoid contents in different solvent extracts of the stem bark of B. variegata were governed by the polarity of the solvent used for extraction. The solubility of flavonoids were higher in polar solvents as evident from the higher concentrations of these compounds in the extracts obtained using polar solvents ${ }^{[20,21]}$. Moreover, the methanolic extract showed higher contents of flavonoid compounds among all the six solvent extracts. The well-known, accurate, and frequently employed method for evaluating antioxidant activity and ability of a compound to scavenge free radicals is the DPPH analysis ${ }^{[22,23]}$.

The reaction between the reactive nitrogen species (NOS) and oxygen leads to the formation of $\mathrm{NO}_{2}, \mathrm{~N}_{2} \mathrm{O}, \mathrm{N}_{3} \mathrm{O}_{4}, \mathrm{NO}_{3}{ }^{-}$and $\mathrm{NO}_{2}{ }^{-}$and thus causing detrimental effects on the structural and functional behaviour of many cellular components ${ }^{[24]}$.Scavenging ROS and NOS could be of importance in management of oxidative stress. In the present study, the findings showed that the methanolic extract of stem bark exhibited more potent inhibition of the nitric oxide in vitro than hydroalcoholic and ethyl acetate extracts. Superoxide free radical produced by alkaline dimethylsulfoxide reacts with nitro blue tetrazolium (NBT) to produce blue coloured diformazan which can be measured at $560 \mathrm{~nm}{ }^{[25]}$. The intensity of blue colour produced is directly proportional to the concentration of superoxide free radical. Taking aforementioned principle as the base, we evaluated the superoxide scavenging potential of different $B$. variegata extracts. The findings of the study revealed that methanolic, hydroalcoholic and ethyl acetate extracts of stem bark of B. variegata showed superoxide scavenging generated by photo reduction of riboflavin, whereas in the chloroform, dichloromethane and n-hexane extract the scavenging activity were very less as compare to all other extracts.

In reducing power assay, the test compounds reduce the $\mathrm{Fe}^{3+}$ into $\mathrm{Fe}^{2+}$ depending on their reducing power, thereby changing the solution into various shades from green to blue which reflects their antioxidants activity ${ }^{[26]}$. Data of the reducing power assay of the tested extracts 
suggested that it is likely to contribute significantly towards the observed antioxidant effect of the different extracts. n-Hexane, chloroform and dichloromethane extracts of stem bark showed less degree of $\mathrm{Fe}^{3+}$ reduction as compared to methanolic, hydroalcoholic and ethyl acetate extracts. Methanolic extracts exhibited more antioxidants and free radical scavenging in all the experimental models when compared with other solvent extracts. This can be directly correlated to the high flavonoid contents which play a major role in prevention of oxidation.

Over the past two decades, the in-depth and remarkable progress has been made in understanding the molecular and cellular mechanisms of cancer and its therapeutic intervention. However, the development of safe and effective regimes for prevention and treatment of cancer remains slow, inefficient, and costly. In particular, the identification of chemotherapeutic and chemopreventive agents that can effectively inhibit cancer development without any toxic side effects plays a central role ${ }^{[27]}$. Many plant-derived compounds such as vinblastine, vincristine, the camptothecin derivatives, topotecan and irinotecan, etoposide derived from epipodophyllotoxin, and paclitaxel have been an important source of several clinically useful anticancer agents ${ }^{[28]}$. The present study clearly indicated that B. variegata extracts possess appreciable in vitro cytotoxic potential against a few selected human cancer cell lines in SRB assay. The differential behaviour of cell lines may be due to different molecular characteristics of these cells. Comparison with growth inhibition activities of standard anticancer drugs (paclitaxel and 5fluorouracil) against all cell lines also demonstrated significant anticancer potential in the test extracts. Our results of the present study revealed that the chloroform extract was the most potent fraction having considerable cytotoxic and anticancer potential against HCT-116 and A549 cell lines whereas, ethyl acetate extract against OVCAR-5 cell lines under investigation. In addition, dichloromethane extract also exhibited substantial cytotoxic activity against only few cancer cell lines. We suggest that the anticancer activity exhibited by the extracts of $B$. variegata could be attributed to the presence of flavonoids in these extracts. Furthermore, research studies reported that flavonoid compounds with proteins, enzymes, and other biological present within the cells serve as growth inhibitors ${ }^{[29,30]}$. Phenolic compounds act as a chemopreventive agent in cancer through their effects on inhibition of carcinogenesis, inhibiting DNA topoisomerase II and p53 downregulation or by causing mitochondrial toxicity, which initiates mitochondrial apoptosis ${ }^{\text {[31] }}$. It has been reported that $B$. variegata stem contains flavonoids which are more selective against different panel of cancer cell lines ${ }^{[32]}$. 


\section{CONCLUSION}

In conclusion, the different extracts of stem bark of B. variegata possessed diverse degree of free radical scavenging activity. Among different extracts, methanol, hydroalcoholic and ethyl acetate extract of stem bark of B. variegata possessed potent antioxidant activities. To the best of our knowledge, this is the first report of such comparative activities for stem bark of B. variegata. Our results revealed that the methanolic extract showed significant free radical-scavenging capacities. Further, detailed work on isolation and characterization of specific chemical moieties from the B. variegata bark extracts and their biological testing can provide us with effective nontoxic antioxidants and antitumor agents in future.

\section{CONFLICT OF INTEREST}

The authors declare that there are no any conflicts of interest. The authors alone are responsible for the content and writing of the paper.

\section{ACKNOWLEDGEMENTS}

The authors are thankful to Dr. Shashank K. Singh, Senior Scientist, Cancer Pharmacology, Indian Institute of Integrative Medicine (IIIM), Jammu. India for providing necessary facility for the in vitro cytotoxicity studies. The authors are also thankful to Mr. Samir Rabadiya, Assistant Professor at Department of Pharmaceutical Sciences, Saurashtra University, Rajkot for their continuous technical support.

\section{REFERENCES}

1. Zheng W, Wang SY. Antioxidant activity and phenolic compounds in selected herbs. J Agric Food Chem 2001;49:5165-70.

2. Gutteridge JM. Free radicals in disease processes: a compilation of cause and consequence. Free Radic Res Commun 1993;19:141-58.

3. Pulido R, Bravo L, Saura-Calixto F. Antioxidant activity of dietary polyphenols as determined by a modified ferric reducing/antioxidant power assay. J Agric Food Chem 2000;48:3396-402.

4. Sumino M, Sekine T, Ruangrungsi N, Igarashi K, Ikegami F. Ardisiphenols and other antioxidant principles from the fruits of Ardisia colorata. Chem Pharm Bull (Tokyo) 2002;50:1484-7.

5. Shajiselvin C, Somasundaram G, Muthu AK. Antioxidant Capacity of Various Extracts from Whole Plant of Bauhinia Purpurea (Linn) Evaluated by Three In Vitro Methods. Pharmacologyonline 2011;1:221-27. 
6. Zakaria Z, Abdul R, Loo Y, Abdul A, Sulaiman M, Mat J, et al. Antinociceptive and antiinflammatory activities of the chloroform extract of Bauhinia purpurea L.(Leguminosae) leaves in animal models. Int J Trop Med 2009;4:140-45.

7. Mishra A, Kumar S, Bhargava A, Sharma B, Pandey A. Studies on in vitro antioxidant and antistaphylococcal activities of some important medicinal plants. Cell Mol Biol 2011;57:16-25.

8. Kumaran A. Antioxidant and free radical scavenging activity of an aqueous extract of Coleus aromaticus. Food Chem 2006;97:109-14.

9. Cuzzocrea S, Riley DP, Caputi AP, Salvemini D. Antioxidant therapy: a new pharmacological approach in shock, inflammation, and ischemia/reperfusion injury. Pharmacol Rev 2001;53:135-59.

10. Gupta D, Chandrashekar K, Lobo R, Nayak Y, Gupta N. In-vitro Antidiabetic activity of stem bark of Bauhinia purpurea Linn. Der Pharmacia Lettre 2012;4:614-19.

11. Sharma S, Kumar A. Tribal uses of medicinal plants of Rajashthan: Kachnar. Int J Life Sc Pharma Res 2012;2:69-76.

12. Pandey S. In vivo antitumor potential of extracts from different parts of Bauhinia variegata linn. Against b16f10 melanoma tumour model in c57bl/6 mice. Applied Cancer Research 2017;37:33.

13. Mishra A, Sharma AK, Kumar S, Saxena AK, Pandey AK. Bauhinia variegata Leaf Extracts Exhibit Considerable Antibacterial, Antioxidant, and Anticancer Activities. BioMed Research International 2013;2013:10.

14. Zhishen J, Mengcheng T, Jianming W. The determination of flavonoid contents in mulberry and their scavenging effects on superoxide radicals. Food Chem 1999;64:55559.

15. Miliauskas G, Venskutonis P, Van Beek T. Screening of radical scavenging activity of some medicinal and aromatic plant extracts. Food Chem 2004;85:231-37.

16. Sreejayan, Rao MN. Nitric oxide scavenging by curcuminoids. J Pharm Pharmacol 1997;49:105-7.

17. Robak J, Gryglewski RJ. Flavonoids are scavengers of superoxide anions. Biochem Pharmacol 1988;37:837-41.

18. Oyaizu M. Studies on products of browning reactions: antioxidant activities of products of browning reaction prepared from glucosamine. J Nutr 1986;44:307-15. 
19. Skehan P, Storeng R, Scudiero D, Monks A, McMahon J, Vistica D, et al. New colorimetric cytotoxicity assay for anticancer-drug screening. J Natl Cancer Inst 1990;82:1107-12.

20. Nagendra PK, Yang B, Yang S, Chen Y, Zhao M, Ashraf M, et al. Identification of phenolic compounds and appraisal of antioxidant and antityrosinase activities from litchi (Litchi sinensis Sonn.) seeds. Food Chem 2009;116:1-7.

21. Gao M, Liu C-Z. Comparison of Techniques for the Extraction of Flavonoids from Cultured Cells of Saussurea medusa Maxim. World J Microbiol Biotechnol 2005;21:1461-63.

22. Zhou K, Yu L. Effects of extraction solvent on wheat bran antioxidant activity estimation. LWT-Food Sci Technol 2004;37:717-21.

23. Chung Y, Chien C, Teng K, Chou S. Antioxidative and mutagenic properties of Zanthoxylum ailanthoides Sieb \& zucc. Food Chem 2006;97:418-25.

24. Moncada S, Palmer RM, Higgs EA. Nitric oxide: physiology, pathophysiology, and pharmacology. Pharmacol Rev 1991;43:109-42.

25. Beauchamp C, Fridovich I. Superoxide dismutase: improved assays and an assay applicable to acrylamide gels. Anal Biochem 1971;44:276-87.

26. Ferreira ICFR, Baptista P, Vilas-Boas M, Barros L. Free-radical scavenging capacity and reducing power of wild edible mushrooms from northeast Portugal: Individual cap and stipe activity. Food Chem 2007;100:1511-16.

27. Kaufmann SH, Earnshaw WC. Induction of apoptosis by cancer chemotherapy. Exp Cell Res 2000;256:42-9.

28. Cragg GM, Newman DJ. Plants as a source of anti-cancer agents. J Ethnopharmacol 2005;100:72-9.

29. Lattanzio V, Lattanzio VMT, Cardinali A. Role of phenolics in the resistance mechanisms of plants against fungal pathogens and insects. Phytochemistry: Advances in Research 2006;37:23-67.

30. Rao YK, Geethangili M, Fang SH, Tzeng YM. Antioxidant and cytotoxic activities of naturally occurring phenolic and related compounds: a comparative study. Food Chem Toxicol 2007;45:1770-6.

31. Nandi S, Vracko M, Bagchi MC. Anticancer activity of selected phenolic compounds: QSAR studies using ridge regression and neural networks. Chem Biol Drug Des 2007;70:424-36. 
32. Ali M, Grever M. A cytotoxic napthoquinone from Lawsonia inermis. Fitoterapia 1998;69:181-83.

AJPHR is

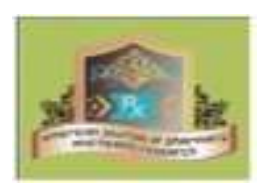

Peer-reviewed

monthly

Rapid publication

Submit your next manuscript at

editor@ajphr.com / editor.ajphr@gmail.com 